\title{
FATIGUE RESISTANCE OF TVPICAL FATIGUE PRONE RIVETED STEEL RAILWAY BRIDGE STRUCTURAL DETAIL
}

There are still a lot of riveted steel railway bridges built in the first half of 20th century in service, and so it is important to pay attention to their evaluation. Their fatigue resistance represents one of the most determining factors on decision making process oriented to possibility of their further exploitation after finishing their planned service life. The standard method of fatigue assessment according to Eurocode EN 1993-1-9 is based on categorization of structural details, which reflects their predisposition to fatigue failure. The paper deals with laboratory investigation of the riveted connection of stringer to cross beam of a railway bridge deck. This structural detail is typical by frequent occurrence of fatigue cracks, but its categorization according to standard mentioned above is at least questionable. In order to investigate and define the fatigue category of this detail more properly, the laboratory tests on specially adapted specimens were performed.

Keywords: bridge fatigue lifetime, fatigue resistance, fatigue detail categorisation, stringer to cross-beam connection.

\section{Introduction}

The aim of fatigue assessment is to verify that the fatigue life of the evaluated structure corresponds to its planned service life time. The assessment is based on evaluating critical structural details prone to fatigue failure, which are classified according to corresponding fatigue categories specified in EN 1993-1-9 [1]. When the detail category is known, the fatigue assessment may be done using the appropriate S-N curve expressing the fatigue life of the detail dependent on the constant cyclic stress range caused by variable load. Since the bridges are specific by stochastic character of the traffic load, the S-N curves used for their fatigue assessment were modified in order to consider a variable spectrum of stress ranges. The riveted connections of stringer to cross-beams in the

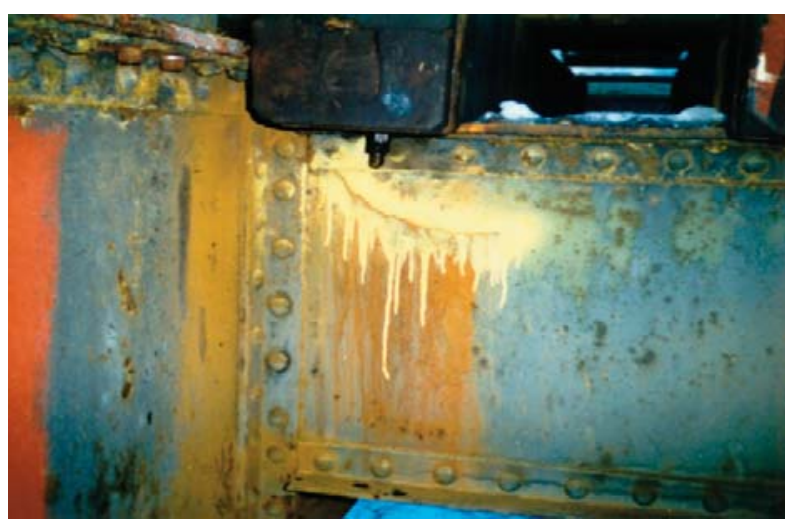

Fig. 1 Example of fatigue crack in the investigated detail case of railway bridges with open bridge decks are typical details prone to fatigue cracks. Webs of stringer and cross-beam are only connected without flange mutual connecting, so that the joint is usually verified on the shear and normal forces only [7]. Due to connection arrangement and certain bending stiffness, the bending moment is arising and producing normal stresses causing the crack in the form given in Fig. 1.

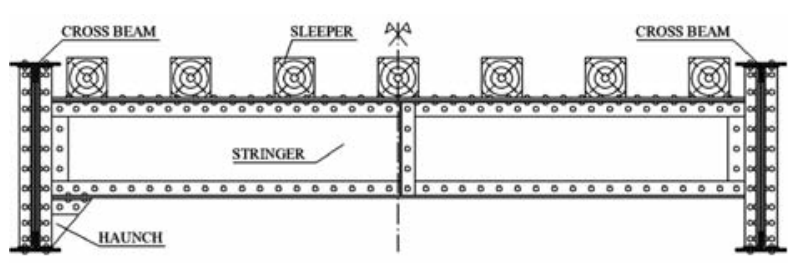

Fig. 2 Arrangement of a typical stringer to cross-beam connection with/without reinforcing haunches

However, in the case of the mentioned type of connection, the fatigue detail categorisation is absent in [1]. Some recommendations for categorization of the riveted details may be found in works of Adamson and Kulak [2] or Matar [3], which deal with riveted details of bridge decks, bracings and connections of bridge decks to main girders, but the detail mentioned above is not able to be categorized even according to these works. Therefore, the laboratory tests of the riveted detail were realized at the Department of structures and bridges to obtain the detail fatigue resistance and to define the detail fatigue categorisation.

\footnotetext{
* Josef Vican, Jozef Gocal, Jozef Jost

Department of Structures and Bridges, Faculty of Civil Engineering, University of Zilina, Slovakia E-mail: josef.vican@fstav.uniza.sk
} 


\section{Laboratory specimens}

Because of limited possibilities of the applied pulsating device as well as due to the economic aspect, the common static scheme of real stringers as a simply supported beam (supported by crossbeams), loaded by reactions from sleepers (see Fig. 2), could not be applied. Therefore, a cantilever loaded by one force at the free end was used as the static scheme for laboratory testing (see Fig. 3) Six specimens were manufactured of steel S235 in all. All specimens consisted of the web from steel plate of P $10 \times 390-1115$ and flanges made of two angles L $80 \times 80 \times 8-995 \mathrm{~mm}$ connected to the web by means of rivets with diameters of $22 \mathrm{~mm}$. Stringer was connected to the hot rolled cross-beam of IPE 700 by means of two angles L $80 \times 80 \times 8-692 \mathrm{~mm}$ using 16 bolts of M $24-8.8$ in the case of specimens of type I and II. Three specimens were reinforced by triangular haunches at the connection to cross-beam (Fig. 3b) and other three specimens were manufactured without the haunches (Fig. 3a).

After testing the six aforesaid specimens, other five specimens of type III (see Fig. 3c) were obtained adjusting the previously tested stringers. The connecting angles were cut off and the new connecting angles $\mathrm{L} 120 \times 120 \times 12-400 \mathrm{~mm}$ were riveted to the free end of the specimens by means of 10 bolts M24 -8.8 . The new connecting angles were shortened compared to previous six specimens in order to situate measuring gauges above the first and below the last rivet, respectively, since the fatigue crack was supposed to develop from this point. Thus, eleven test specimens were tested altogether. One of the specimens was used for destructive tests to determine the material characteristics. The following material characteristics were obtained by testing - the yield strength $f_{y}=244.92 \mathrm{MPa}$ and the ultimate strength $f_{u}=360.77 \mathrm{MPa}$.

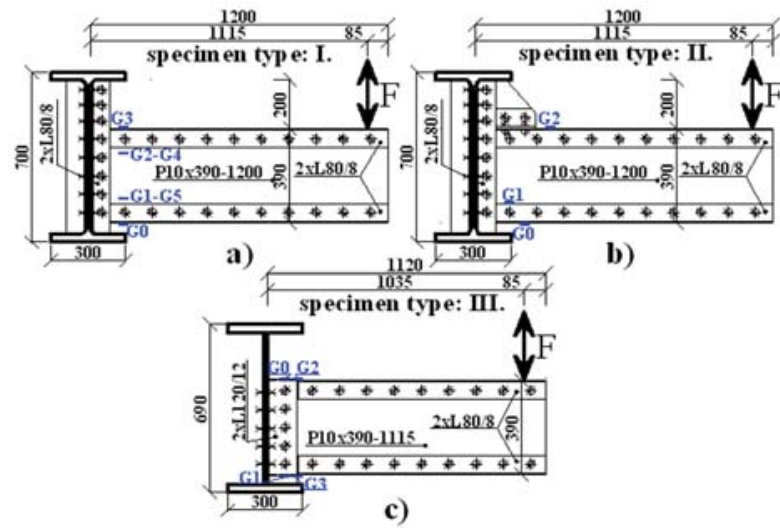

Fig. 3 Configuration of laboratory specimens without haunch (I), reinforced by haunch (II) and new specimens without haunch (III) and specimen gauge arrangement

\section{Laboratory testing process}

Firstly, the numerical calculations of the tested detail were accomplished using software SCIA Engineer to determine required maximum and minimum forces causing the needed stress ranges. The specimen types I and II were tested in 2009 and the testing process as well as the test results were described in [4]. Other five new specimens were tested in the laboratory of Transport Research Institute in Zilina from January to April 2010.

All the specimens were gradually subjected to fluctuating bending moment through the application of concentrated vertical load situated at the distance $1115 \mathrm{~mm}$ from the supporting crossbeam (see Fig. 3), in the case of specimen type I and II and 1035 $\mathrm{mm}$, in the case of specimen type III, respectively. For all specimens, the loading force was floating between positive and negative limit values (see Fig. 3). At the start of fatigue test, each specimen was loaded statically at the maximum and minimum values of the loads that would be applied during the fatigue test. In the case of specimens with reinforcing triangular haunches the absolute values of maximum (positive) and minimum (negative) loading forces were different, i.e. the normal stresses in the observed points of the stringer web (see Fig. 3a) oscillated around the mean stress different from zero. In the case of specimens without haunches the absolute values of maximum (positive) and minimum (negative) loading forces were the same, i.e. the normal stresses in the observed points of the stringer web (see Fig. 3b) oscillated around the mean stress close to zero.

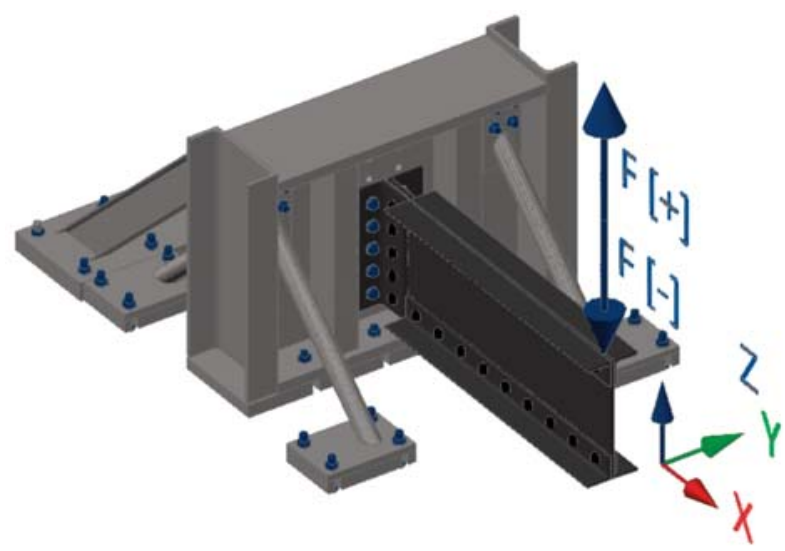

Fig. 4 Configuration of a laboratory specimen and the pulsating forces

Normal stresses in the stringer web were measured by means of gauges LY11-6/120 manufactured by Hottinger-Baldwin Messtechnik [6]. Location of gauges is shown in Fig. 3. Measured data was recorded by measuring equipment Spider 8 , controlled by computer software Catman. Fatigue test arrangement is shown in Fig. 5.

\section{Experimental results}

The results of the experimental fatigue tests of the specimens described above are presented in the form of stress ranges and corresponding numbers of cycles to failure in Table 1. Specimens No. 1 - 6 had been tested previously, specimens of No. 7 - 10 rep- 

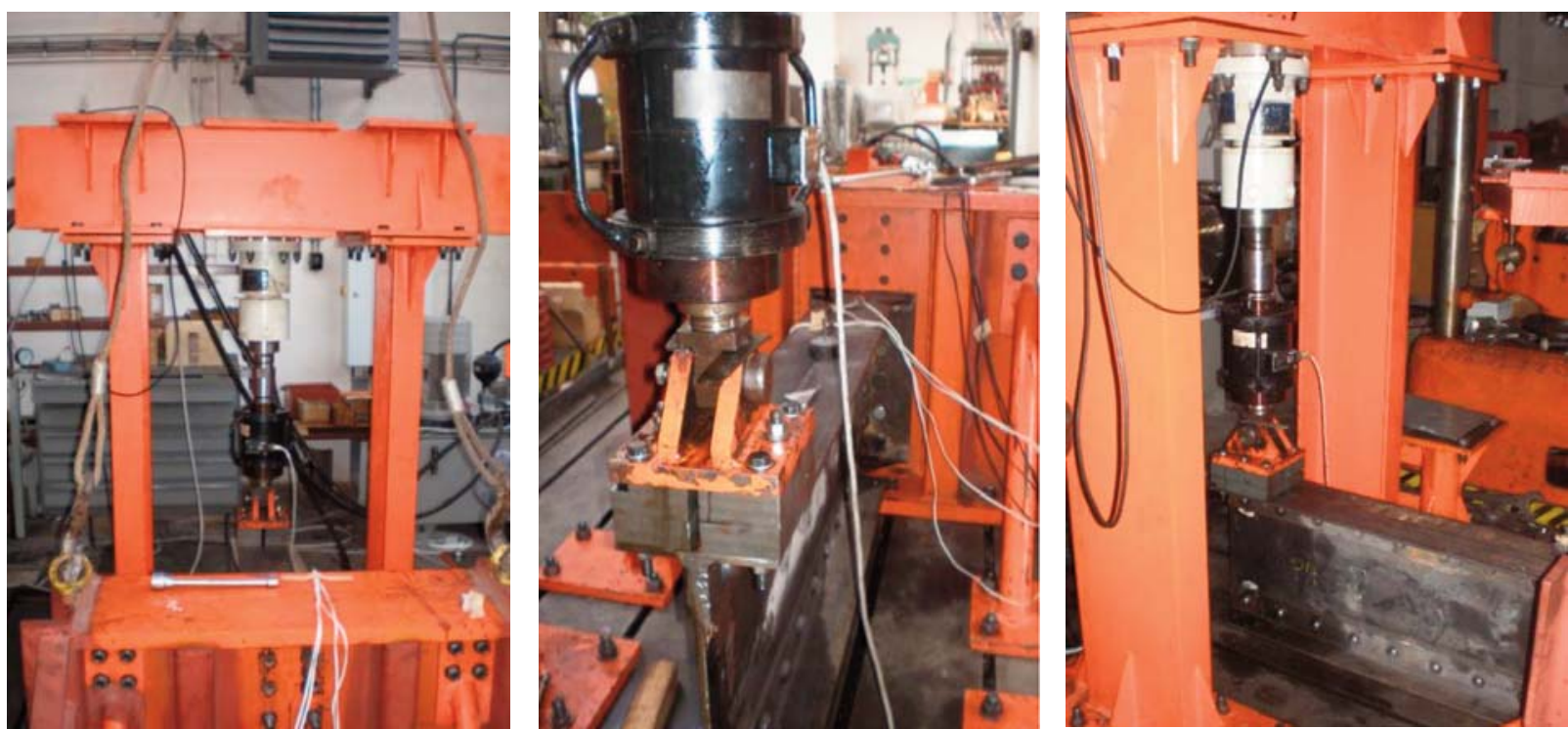

Fig. 5 Illustration photos from fatigue tests

resent the results of the last tests in 2010. As it was mentioned above, eleven specimens altogether were experimentally investigated, but one specimen failed due to cracks in connecting angle, so that its result had to be rejected. In order to avoid this type of failure, the remaining four specimens were reinforced by means of triangular sheets welded between angle flanges according to Fig. 6 .
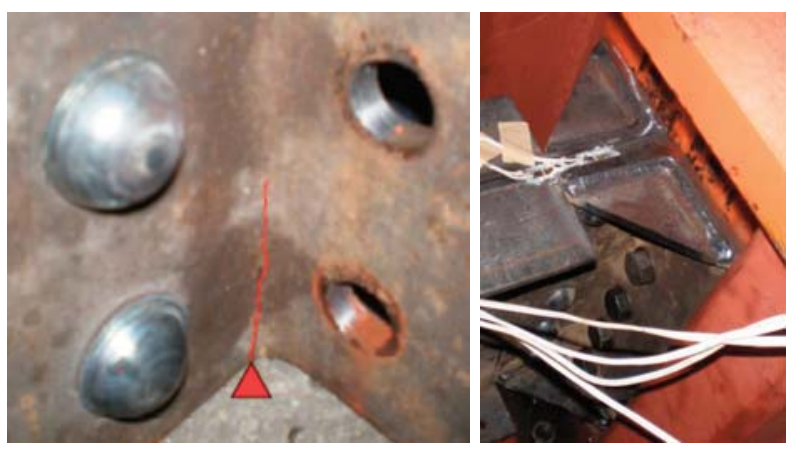

Fig. 6 Failure of specimen due to crack in the angle and reinforcement of this detail

Typical failure of the investigated detail is presented in Fig. 7 Picture on the left side shows the out-of-roundness of the hole diameter due to material cyclic plasticity after which the beam global deflection is rapidly growing. The picture on the right side shows the classic type of fatigue failure in the form of crack starting from the rivet hole.

Since the standard $S-N$ curves are derived for fully reversed alternating stresses (stress ratio $R=\sigma_{\min } / \sigma_{\max }=-1$, mean stress $\sigma_{m}=0$ ), the measured stresses alternating around the nonzero mean stress $\left(\sigma_{m} \neq 0\right)$ in the case of specimens of type II had to be modified. The Goodman's mean stress correction relationship

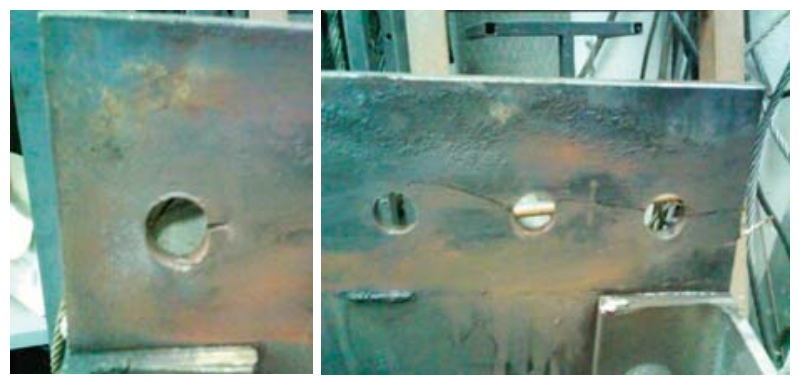

Fig. 7 Types of detail fatigue failures

was applied, which defines the equivalent stress amplitude $\sigma_{e}=0$ corresponding to the mean stress $\sigma_{m}=0$ by the following equation

$$
\sigma_{e}=\frac{\sigma_{a}}{1-\frac{\sigma_{m}}{f_{u}}},
$$

where $\sigma_{a}$ is stress amplitude corresponding to the mean stress $\sigma_{m} \neq 0$ and $f_{u}$ is the ultimate material strength.

Different form of the cracks in the real bridge stringer webs (see Fig. 1) and the ones in tested specimens (see Fig. 7) was caused due to discrepant stringer static system. While stringer in Fig. 1 seems to be quasi simple supported beam, the static system of the tested stringers is cantilever (see Figs. 4 and 5).

These results were subjected to linear regressive analysis (see Fig. 8) according to the Appendix L in STN 73 1401[5], in which $\log \Delta \sigma$ represents an independent variable and $\log \mathrm{N}$ represents a dependent variable with normal probability distribution. Based on the regressive analysis results, the fatigue resistance of investigated detail corresponding to $2 \times 10^{6}$ cycles is $\Delta \sigma_{C}=83.9 \mathrm{MPa}$. 
Results of fatigue tests

\begin{tabular}{|c|c|c|}
\hline $\begin{array}{c}\text { Specimen } \\
\text { No. }\end{array}$ & $\begin{array}{c}\text { Equivalent stress range } \Delta \sigma_{e} \\
{[\mathrm{MPa}]}\end{array}$ & $\begin{array}{c}\text { Number of cycles to failure } \\
\text { N [cycles] }\end{array}$ \\
\hline 1 & 114.9 & 1276750 \\
\hline 2 & 136.6 & 571000 \\
\hline 3 & 88.0 & 3653000 \\
\hline 4 & 97.2 & 2218900 \\
\hline 5 & 147.7 & 629000 \\
\hline 6 & 125.4 & 798350 \\
\hline 7 & 121.7 & 1240450 \\
\hline 8 & 116.3 & 1863760 \\
\hline 9 & 142.5 & 1406080 \\
\hline 10 & 119.0 & 1697600 \\
\hline
\end{tabular}

Therefore, the detail can be classified to the category 80 with characteristic fatigue strength $\Delta \sigma_{C}=80 \mathrm{MPa}$ in accordance with [1].

\section{Conclusion}

The paper deals with experimental investigation of the fatigue resistance of the stringer to cross-beam riveted connection representing the common fatigue prone structural detail of existing steel railway bridges with open decks. After collection of all experimental data from tests realized in 2009 and 2010 and based on the obtained results of all performed fatigue tests, the detail could be classified to the category 80 according to EN 1993-1-9 [1].

\section{Acknowledgements}

This work was supported by the Scientific Grant Agency of the Slovak Republic under the project 1/0311/09 "Durability of the steel bridge structural members".

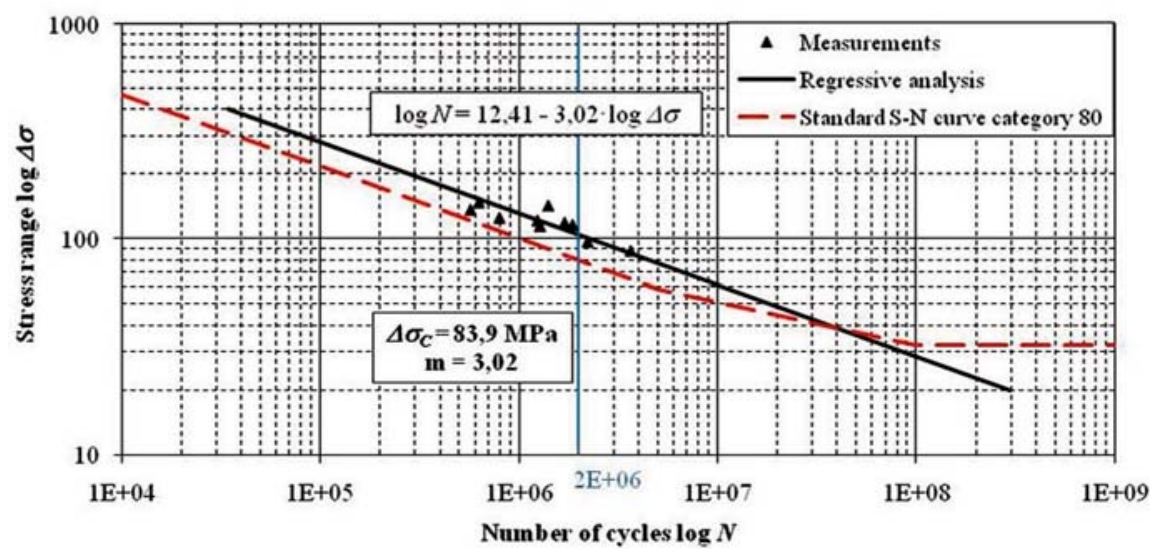

Fig. 8 Results of fatigue tests

\section{References}

[1] EN 1993-1-9, Eurocode 3: Design of Steel Structures, Part 1.9, Fatigue, Brussels, 2003.

[2] ADAMSON, D., KULAK, G.: Fatigue Tests of Riveted Bridge Girders, Structural Engineering Report, No. 210, University of Alberta., 1995.

[3] MATAR, E. B.: Evaluation of Fatigue Category of Riveted Steel Bridge Connections. Structural Eng. Int'l, No. 1, 2007, pp. $72-78$.

[4] GOCAL, J., VICAN, J., HLINKA, R., JOST, J.: Laboratory Tests of a Typical Fatigue Prone Riveted Steel Railway Bridge Structural Detail, Procedia Engineering 2, 2010, ScienceDirect, Elsevier 2010, pp. 1761-1766.

[5] STN 731401 Design of Steel Structures, SUTN Bratislava 1998.

[6] TREBUNA, R., SIMCAK, F.: Handbook of Experimental Mechanics, Edition of the Scientific and Technical Literature, Kosice, 2007.

[7] VICAN, J., GOCAL, J., MELIS, B., KOTES, P., KOTULA, P: Real Behaviour and Remaining Lifetime of Bridge Structures, Communications - Scientific Letters of the University of Zilina, Vol. 2, 2008, ISSN 1335-4205, pp. 30-37.

[8] KALA, Z., PUKLICKY, L., OMISHORE, A., KARMAZINOVA, M., MELCHER, J.: Stability Problems of Steel-concrete Members Composed of High-strenght Materials. J. of Civil Eng. and Management, 2010, ISSN 1392-3730 print/ISSN 1822-3605 online, doi: 10.3846/jcem.2010.40, pp. 352-362, http: www.jcem.vgtu.It. 